\title{
Long-term outcomes after immediate aortic repair for acute type A aortic dissection complicated by coma
}

\author{
Takuro Tsukube, MD, PhD, ${ }^{\mathrm{a}}$ Tomonori Haraguchi, MD, PhD, ${ }^{\mathrm{a}}$ Yasushi Okada, MD, ${ }^{\mathrm{a}}$ \\ Ritsu Matsukawa, MD, PhD, ${ }^{a}$ Shuichi Kozawa, MD, PhD, ${ }^{a}$ Kyoichi Ogawa, MD, PhD, ${ }^{a}$ and \\ Yutaka Okita, MD, $\mathrm{PhD}^{\mathrm{b}}$
}

\begin{abstract}
Objectives: The management of acute type A aortic dissection complicated by coma remains controversial. We previously reported an excellent rate of recovery of consciousness provided aortic repair was performed within 5 hours of the onset of symptoms. This study evaluates the early and long-term outcomes using this approach.
\end{abstract}

\begin{abstract}
Methods: Between August 2003 and July 2013, of the 241 patients with acute type A aortic dissection brought to the Japanese Red Cross Kobe Hospital and Hyogo Emergency Medical Center, 30 (12.4\%) presented with coma; Glasgow Coma Scale was less than 11 on arrival. Surgery was performed in 186 patients, including $27(14.5 \%)$ who were comatose. Twenty-four comatose patients underwent successful aortic repair immediately (immediate group). Their mean age was $71.0 \pm 11.1$ years, Glasgow Coma Scale was $6.5 \pm 2.4$, and prevalence of carotid dissection was $79 \%$. For brain protection, deep hypothermia with antegrade cerebral perfusion was used, and postoperative induced hypothermia was performed. Neurologic evaluations were performed using the Glasgow Coma Scale, National Institutes of Health Stroke Scale, and modified Rankin Scale.
\end{abstract}

Results: In the immediate group, the time from the onset of symptoms to arrival in the operating theater was 222 \pm 86 minutes. Hospital mortality was $12.5 \%$. Full recovery of consciousness was achieved in $79 \%$ of patients in up to 30 days. Postoperative Glasgow Coma Scale and National Institutes of Health Stroke Scale improved significantly when compared with the preoperative score $(P<.05)$, and postoperative activities of daily living independence (modified Rankin Scale $<3$ ) was achieved in $50 \%$ of patients. The mean follow-up period was 56.5 months, and the cumulative survival was $48.2 \%$ after 10 years. Cox proportional hazards regression analysis indicated that immediate repair (hazard ratio, $4.3 ; P=.007$ ) was the only significant predictor of postoperative survival over a 5-year period.

Conclusions: The early and long-term outcomes as a result of immediate aortic repair for acute type A aortic dissection complicated by coma were satisfactory. (J Thorac Cardiovasc Surg 2014;148:1013-9)

Neurologic outcomes are a primary concern $^{1-3}$ if aortic repair of acute type A aortic dissection (AADA) is performed in the setting of preoperative coma. The new onset of hemorrhagic conversion of ischemic stroke or massive brain edema after reperfusion of the cerebral circulation also might be induced. However, recent studies have shown that surgical repair of AADA can be performed in the setting of preoperative stroke with acceptable mortality, and that immediate surgical repair is warranted even if AADA is complicated by stroke. ${ }^{4,5}$ In

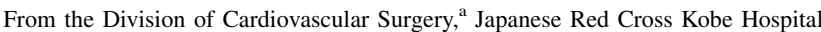
and Hyogo Emergency Medical Center, Kobe, Japan; and the Division of Cardiovascular Surgery, ${ }^{\mathrm{b}}$ Graduate School of Medicine, Kobe University, Kobe, Japan.

Disclosures: Authors have nothing to disclose with regard to commercial support.

Read at the 94th Annual Meeting of The American Association for Thoracic Surgery, Toronto, Ontario, Canada, April 26-30, 2014.

Received for publication April 9, 2014; revisions received June 26, 2014; accepted for publication June 30, 2014.

Address for reprints: Takuro Tsukube, MD, PhD, Division of Cardiovascular Surgery, Japanese Red Cross Kobe Hospital, 1-3-1 Wakihama-kaigandori Chuo-ku, Kobe, Japan 651-0073 (E-mail: t-tsukube@kobe.jrc.or.jp).

$0022-5223 / \$ 36.00$

Copyright (c) 2014 by The American Association for Thoracic Surgery

http://dx.doi.org/10.1016/j.jtcvs.2014.06.053
}

addition, Estrera and colleagues ${ }^{4}$ reported that no hemorrhagic conversion of ischemic stroke was observed in their 14 surgical patients, despite the use of full anticoagulation. ${ }^{4}$ For patients with AADA complicated by coma, we have reported an excellent recovery of consciousness, as long as aortic repair is performed within several hours from the onset of symptoms. ${ }^{6}$

In addition, as our report shows, in 21 cases of brain ischemia in which immediate aortic repair under full heparinization was involved, not a single case of postoperative intracerebral hemorrhage was observed.

A recent report from the International Registry for Acute Dissection (IRAD) showed that among patients selected to undergo aortic repair, the chances of late survival improved, along with the frequent reversal of neurologic deficits. ${ }^{7}$ The IRAD report of 141 patients with AADA presenting with cerebrovascular accident (CVA) or coma strongly supports the study reported by Estrera and colleagues. ${ }^{4}$ The IRAD report also supports our study, ${ }^{6}$ in which brain injury reversal is likely after surgery in selected patients, occurring in $80.4 \%$ and $74.2 \%$ of patients with CVA and coma, respectively. However, long-term outcomes after aortic repair remain unclear. The purpose of this study is to report 


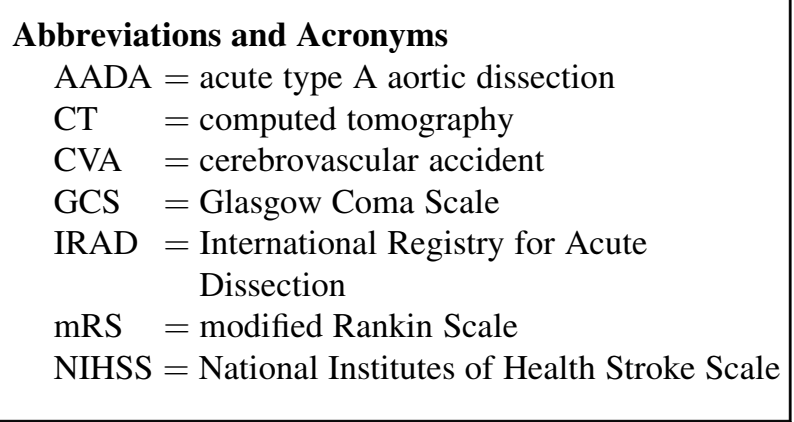

and analyze our single-center results of immediate aortic repair for patients with AADA complicated by coma.

\section{METHODS \\ Patient Characteristics}

Between August 2003 and July 2013, 241 patients consecutively presented with AADA at the Japanese Red Cross Kobe Hospital and Hyogo Emergency Medical Center and 186 patients underwent aortic repair. Of the 186 surgical patients, 27 were in preoperative coma, 10 had a neurologic deficit due to cerebral malperfusion without coma, and 147 were neurologically intact preoperatively. Twenty-one patients were treated medically, including 3 comatose patients who arrived at some time after the onset of coma, 16 with thrombosed false lumen in the ascending aorta, and 2 who were already bedridden. Twenty-nine patients died of cardiopulmonary arrest on arrival at the hospital emergency department. After excluding these 29 patients, 30 other patients were comatose on arrival. The mean age of the patients was 72.4 years (range, $44-91$ years; standard deviation, 11.3), and $33 \%$ were male. Of the 30 patients with preoperative coma, 24 underwent immediate aortic repair (immediate group) and 6 received initial medical treatment (initially medical group). Of the 6 patients in the initially medical group, 3 eventually underwent aortic repair and 3 had irreparable neurologic damage and died during medical treatment.

\section{Neurologic Evaluation}

Three neurologic scales- the Glasgow Coma Scale (GCS), the National Institutes of Health Stroke Scale (NIHSS), ${ }^{8}$ and a modified Rankin Scale $(\mathrm{mRS})^{9}$ - were used to evaluate the effect on neurologic outcomes. The GCS was used to assess the level of consciousness, and the NIHSS was used to quantify the clinical severity of the stroke, which includes the levels of consciousness, language, neglect, visual-field loss, extraocular movement, motor strength, ataxia, dysarthria, and sensory loss. Both the GCS and the NIHSS were used to assist preoperative and early postoperative evaluation. Coma was defined on arrival at the hospital as less than 11 on the GCS, with a mean GCS score of 6.5 (range, 3-10). Patients with a transient consciousness disturbance were not included in this study. To evaluate late neurologic outcomes, $\mathrm{mRS}$ was used to determine the degree of dependence in the daily activities of patients who had experienced neurologic injuries. ${ }^{9}$ Initial clinical diagnosis was performed by the emergency center team at Hyogo Emergency Medical Center, the neurologists from Kobe Red Cross Hospital Stroke Team, or the cardiovascular team. Neurologists reevaluated the preoperative and postoperative neurologic scales of all of the comatose patients directly or using hospital records.

\section{Treatment}

In cases in which aortic disease was suspected on arrival at hospital, we performed a computed tomography (CT) scan of the aorta in all patients and a brain CT scan if any neurologic disorder was present to arrive at a definitive diagnosis. Magnetic resonance imaging of the brain was performed on 2 comatose patients before diagnosis of AADA elsewhere. The patients were then transported to our hospital. Patients who presented with a coma were taken to the operating room as quickly as possible. During the initial treatment, controlled pericardial drainage was performed in 9 patients to treat cardiac tamponade. ${ }^{10}$ Twenty-four comatose patients underwent immediate aortic repair (immediate group). However, if a definitive diagnosis was made more than several hours after the onset of symptoms, the patient was initially given nonsurgical treatment. Six comatose patients were managed medically, and 3 patients whose GCS level $(8.7 \pm 2.3)$ underwent delayed aortic repair (initially medical group). The overall in-hospital mortality of all patients who underwent aortic repair was $11.3 \%(21 / 186)$.

\section{Operative Approach}

The aortic repairs were conducted via a median sternotomy, using full heparinization, cardiopulmonary bypass, and profound hypothermic circulatory arrest with antegrade cerebral perfusion. Arterial cannulation was accessed via the femoral artery $(\mathrm{n}=24)$, both the femoral and axillary arteries $(\mathrm{n}=1)$, or both the femoral artery and the ascending aorta $(\mathrm{n}=2)$. Cerebral function was continuously monitored using the Bispectral Index (Aspect Medical Systems, Inc, Norwood, Mass). Regional oxygen saturation was monitored using the INVOS 5100 Cerebral Oximeter (Somanetics, Inc, Troy, Mich). Once a nasopharyngeal temperature of $18^{\circ} \mathrm{C}$ and a rectal temperature of $25^{\circ} \mathrm{C}$ had been attained, cardiopulmonary bypass was discontinued and circulation was arrested. Antegrade perfusion of the left subclavian artery, left common carotid artery, and innominate artery was commenced by means of direct cannulation into the true lumen from the orifices. In 20 patients, the intimal tear was isolated to the proximal transverse aortic arch, and a hemiarch replacement was performed. Total arch replacement was performed in 7 patients. An additional carotid arterial repair in the neck region to exclude false lumen was not attempted in any of the patients. The mean cerebral perfusion time in 27 patients was $75 \pm 39$ minutes, with a mean cardiopulmonary bypass time of $270 \pm 48$ minutes. After reconstruction of the distal end of the aorta and arch branches, systemic warming was started. Rewarming was controlled slowly until a rectal temperature of $34^{\circ} \mathrm{C}$ was achieved.

\section{Postoperative Care}

All patients were admitted to the intensive care unit and given a course of therapeutic hypothermia using water blankets to keep their body temperature at less than $36.0^{\circ} \mathrm{C}$ for 24 hours.

Magnesium sulfate was infused continuously to maintain the ionized magnesium $\left(\mathrm{Mg}^{++}\right)$level between 0.7 and $1.0 \mathrm{mmol} / \mathrm{L}$ throughout the operative procedure and during postoperative care. In our protocol, magnesium sulfate solution $(0.5 \mathrm{~mol} / \mathrm{L})$ was infused at $3.2 \mathrm{~mL} / \mathrm{kg} / \mathrm{h}$ for the first 15 minutes, followed by $0.1 \mathrm{~mL} / \mathrm{kg} / \mathrm{h}$ for 24 hours. $^{6}$

\section{Statistical Analysis}

The Kobe Red Cross Hospital and Hyogo Emergency Medical Center Committee for the Protection of Human Subjects approved the data collection and analysis. Analysis was retrospective. Data were collected from chart reviews by the authors (T.T., T.H.). Categoric variables are described as number and percent and were analyzed with a 2-tailed Fisher exact test where appropriate. Continuous variables are described as mean \pm standard deviation and were analyzed by 2 -way repeated-measures analysis of variance to evaluate the main effect of group and time. The variables that achieved a $P$ value less than .15 on univariate analysis were introduced to a multivariate analysis by backward stepwise logistic regression to estimate the independent adjusted odds ratio of factors related to hospital death and neurologic outcomes. Survival analysis was performed according to the Kaplan-Meier method, and statistical differences were analyzed using the log-rank test. Data analyses were performed with SPSS software (version 17.0; SPSS, Inc, Chicago, Ill). 
TABLE 1. Patient characteristics

\begin{tabular}{|c|c|c|c|}
\hline & $\begin{array}{c}\text { Immediate } \\
\text { group }(n=24)\end{array}$ & $\begin{array}{c}\text { Initially medical } \\
\text { group }(n=6)\end{array}$ & $\boldsymbol{P}$ \\
\hline Age, y & $71.0 \pm 11.0$ & $76.0 \pm 11.8$ & NS \\
\hline Male & $9(38)$ & $1(17)$ & NS \\
\hline GCS & $6.6 \pm 2.4$ & $6.5 \pm 3.1$ & NS \\
\hline Shock on arrival & $16(67)$ & $5(83)$ & NS \\
\hline Pericardial effusion & $17(71)$ & $5(83)$ & NS \\
\hline CPD performed & $9(38)$ & $3(50)$ & NS \\
\hline Carotid dissection & $19(79)$ & $4(67)$ & NS \\
\hline NIHSS & $30.7 \pm 7.0$ & $28.3 \pm 9.5$ & NS \\
\hline Aortic repair performed & $24(100)$ & $3(50)$ & .004 \\
\hline Time from onset to $\mathrm{OR}$, $\mathrm{min}$ & $222 \pm 86$ & $2129 \pm 501$ & .005 \\
\hline \multicolumn{4}{|l|}{ Operative procedure } \\
\hline Total arch replacement & $7(29)$ & $0(0)$ & NS \\
\hline Hemiarch replacement & $17(71)$ & $3(100)$ & \\
\hline \multicolumn{4}{|l|}{ Post-treatment } \\
\hline In-hospital mortality & $3(13)$ & $4(67)$ & .027 \\
\hline Intracerebral hemorrhage & $0(0)$ & $0(0)$ & NS \\
\hline Full recovery of consciousness & $19(79)^{*}$ & $1(16)$ & .006 \\
\hline NIHSS (D/C) & $8.5 \pm 10.9 \dagger$ & $29.7 \pm 16.7$ & .021 \\
\hline modified Rankin Scale (mRS) & $3.0 \pm 2.2$ & $5.2 \pm 1.6$ & .038 \\
\hline mRS 0-2 & $12(50)$ & $1(16)$ & NS \\
\hline mRS 3-6 & $12(50)$ & $5(84)$ & NS \\
\hline
\end{tabular}

$C P D$, Controlled pericardial drainage; $D / C$, discharge; $G C S$, Glasgow Coma Scale; $m R S$, modified Rankin Scale; NIHSS, National Institutes of Health Stroke Scale; $N S$, not significant; $O R$, operating room. $*<0.0001$ when compared with preoperative consciousness. $\dagger<0.0001$ when compared with preoperative NIHSS

\section{RESULTS}

\section{Patient Characteristics and Postoperative Mortality and Morbidity}

Preoperative patient characteristics, procedures, and operative mortality and morbidities are listed in Table 1. In-hospital mortality was $12.5 \%$ (3/24) among patients in the immediate group, and 21 patients survived. There was no statistical difference between this and the overall inhospital mortality of 186 patients $(11.3 \%)$. The causes of death of patients in the immediate group included rupture of the descending aorta, acute myocardial infarction, and massive brain edema. Postoperative brain CT scans were performed on all patients, and none in the immediate group showed intracerebral hemorrhage.

Complete recovery of consciousness was achieved postoperatively in $63 \%(15 / 24)$ of patients within 14 days, and only 5 patients remained in a state of partial consciousness during the follow-up period in the immediate group. Therefore, $79 \%(19 / 24)$ of patients completely regained consciousness in 30 days, and there was a significant statistical improvement in overall consciousness $(P<.0001)$.

Postoperative functional recovery, assessed by improvement of NIHSS score, improved significantly in the immediate group. The postoperative NIHSS score was $8.5 \pm 10.8$, which was significantly lower than the preoperative NIHSS score $(P<.0001)$. However, major neurologic deficits were observed in $42 \%$ of patients (10/24), including monoparesis in 1 patients, left hemiparesis in 2 patients, left hemiplegia in 3 patients, aphasia with left hemiplegia in 1 patient, quadriparesis in 1 patient, and quadriplegia with consistent coma in 2 patients.

In the initially medical group of patients, in-hospital mortality was $66.7 \%$ (4/6). Three patients underwent aortic repair, resulting in only 1 patient completely regaining consciousness. The postoperative NIHSS score was $29.7 \pm$ 16.7, which was significantly higher than the score in the immediate group. According to logistic regression analysis, the only independent predictor of in-hospital death was initial medical treatment (odds ratio, $17.333 ; 95 \%$ confidence interval, 1.387-216.565; $P=.027$ ).

By contrast, the postoperative new onset of neurologic deficits appeared in $6.9 \%(10 / 144)$ of patients whose preoperative neurologic function was intact, whereas neurologic deficits remained in $33 \%(5 / 15)$ of noncomatose patients with preoperative neurologic deficits. There was a statistically significant difference in the incidence of postoperative neurologic deficits between comatose and neurologically intact patients $(P<.0001)$.

\section{Long-Term Outcomes and Dependence in Daily Activities}

In the immediate group, 21 patients were discharged from the hospital and 2 patients underwent surgical procedures during the follow-up periods, including aortic root replacement and aortic valve replacement. The mean follow-up period was $55.6 \pm 42.7$ months; 7 patients died, and the cumulative survival was $60.3 \%$ after 5 years and $48.2 \%$ after 10 years (Figure 1, $A$ ). The causes of death included heart failure in 1 patient, pneumonia in 3 patients, residual CVA in 2 patients, and unexplained sudden death in 1 patient. There were significant differences in survival between comatose patients who underwent immediate aortic repair and noncomatose patients who underwent aortic repair $(P=.028)$, and between the immediate group and the initially medical group $(P=.0008)$ (Figure $1, A)$.

During the follow-up period, mRS was used to assess functional neurologic recovery. Table 2 shows the 1-year postoperative functional recovery rate of patients in the immediate and initially medical groups. In the immediate group, independence in daily life, which was determined if mRS was less than 3, was achieved in $50 \%$ of patients (12/24). Complete functional recovery, determined if mRS was less than 2 , was obtained in $33.3 \%$ of patients $(8 / 24)$, whereas $16.7 \%$ of patients (4/24) with an mRS of 0 were neurologically normal.

Figure 1, $B$ shows that patients with $\mathrm{mRS}$ less than 2 had a significantly better survival than patients with $\mathrm{mRS}$ greater than $3(n=0.0006)$. There was a strong correlation between independence in daily activities and longer survival. Cox proportional hazards regression analysis indicated that immediate aortic repair (hazard ratio, $4.3 ; 95 \%$ confidence 

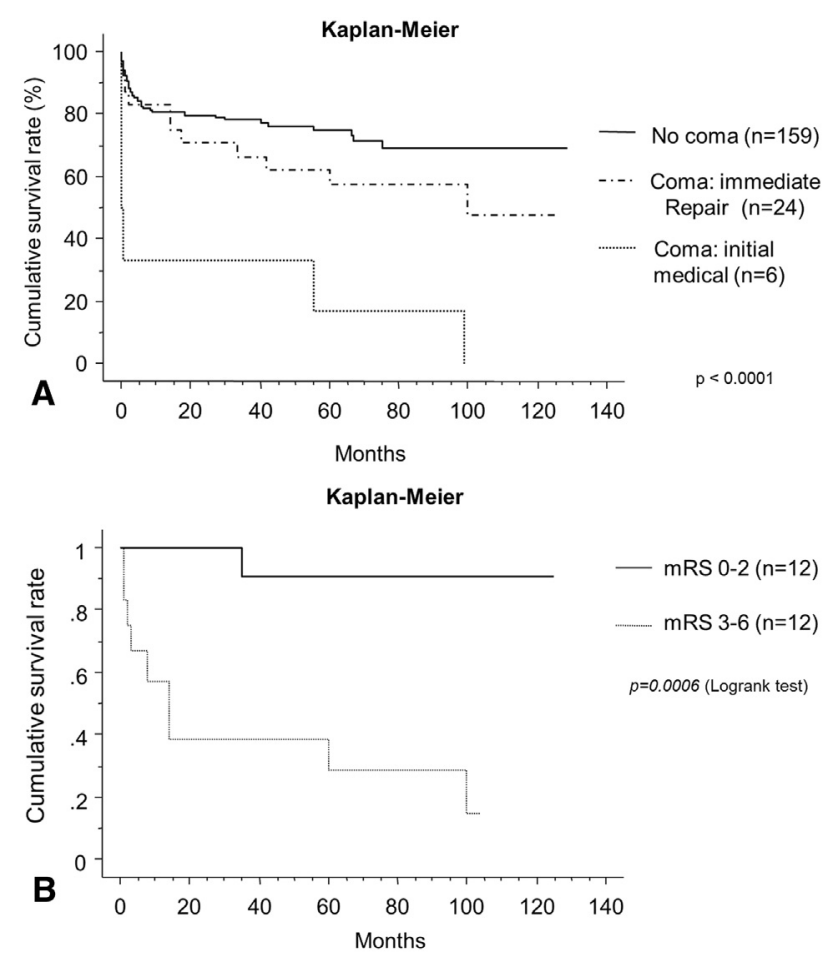

FIGURE 1. A, Cumulative survival of all patients with AADA. Patients were divided into 3 groups: noncomatose group $(n=159)$, coma and immediate repair group $(\mathrm{n}=24)$, and coma and initial medical group $(\mathrm{n}=30)$. B, Cumulative survival of patients in the immediate repair group of AADA: Patients were divided into 2 groups by postoperative mRS. $m R S$, modified Rankin Scale.

interval, $1.480-12.240 ; P=.007$ ) was the only significant predictor of 5-year postoperative survival among preoperative variables.

\section{DISCUSSION}

In the past, the intentional delay of aortic repair was recommended for patients with AADA presenting with a neurologic deficit. ${ }^{11}$ Cambria and colleagues ${ }^{12}$ reported that 6 of 7 patients with preoperative cerebral infarction and aortic dissection died of brain damage after aortic repair. Several authors have reported a strong correlation between mortality rates and strokes in patients with AADA. ${ }^{11-15}$

However, the intentional surgical delay may not contribute to the survival of patients. In our study, there was a $67 \%$ mortality rate among 6 patients who underwent intentionally delayed surgery. High mortality was related to conflicting therapeutic strategies in patients with AADA experiencing acute strokes. To improve the brain circulation of patients who have had an acute stroke, blood pressure must be kept higher and thrombolytic therapy must be applied if necessary. However, these management strategies could result in death from aortic rupture, cardiac tamponade, or retrograde dissection with coronary artery involvement, ${ }^{16}$ and so should not be applied. DiEusanio and colleagues ${ }^{7}$ reported that of 1873 patients with AADA who were enrolled in the IRAD, 84 had presented with CVA and 54 had presented with coma. Among 54 comatose patients, medical management was selected for 18. Not 1 patient survived, and the in-hospital mortality rate was $100 \%$. Therefore, an intentionally delayed approach entails clearly conflicting therapies and is not recommended as a treatment option for comatose patients with AADA.

Several recent studies of early surgical repair have been reported in relation to patients with AADA complicated with CVA or coma (Table 3). ${ }^{1,4-7,17,18}$ Most of the studies reported favorable results and recommended early surgical intervention. Pocar and colleagues ${ }^{5}$ reported that when surgical repairs of AADA were performed on 5 comatose patients within 9 hours of the onset of coma, no operative deaths, postoperative hemorrhagic infarctions, or severe brain edemas were observed. However, they did report that the prevalence of those conditions can be higher when there is a longer interval before surgical repair or in older patients. ${ }^{5}$ Estrera and colleagues ${ }^{4}$ reported that surgical repair of AADA could be performed safely when preoperative stroke occurs, with no hemorrhagic conversion of ischemic stroke. In their 14 surgical patients, $80 \%$ who underwent surgical repair within 10 hours from the onset of stroke had improved neurologic status, whereas none of those operated on beyond 10 hours showed any improvement. We previously reported that if the time between the onset of stroke to the operating room was less than 5 hours, hospital mortality was $14 \%$ and full recovery of consciousness was achieved in $86 \%$ of patients. Our results are comparable to those demonstrated by Estrera and colleagues ${ }^{4}$ in which 4 patients underwent operation within 5 hours from the onset of symptoms, with 3 of them showing a marked improvement. In addition, Estrera and colleagues ${ }^{4}$ observed no hemorrhagic conversion of ischemic stroke in their 14 surgical patients, despite the use of full anticoagulation. Likewise, we did not observe any cases of intracerebral hemorrhage. Morimoto and colleagues ${ }^{17}$ reported that of 41 patients undergoing operation for AADA complicated by cerebral malperfusion, no neurologic improvement was observed in $15(37 \%)$. The time between the onset of symptoms and the surgery, and preoperative NIHSS scores were predictors of lack of improvement, which was in turn associated with poor survival. An NIHSS greater than 11 and a period of 9.1 hours between the onset of symptoms and the surgery were reported to be the most reliable cutoff points in predicting a lack of neurologic improvement. All of the studies demonstrated a strong correlation between the time from onset to surgery and the outcomes, and showed that hemorrhagic conversion in the brain was uncommon when early surgical repair was performed, despite the use of full anticoagulation. ${ }^{4-6,17}$ 
TABLE 2. Distribution of modified Rankin Scale 1 year after aortic repair

\begin{tabular}{lcc}
\hline Score & Immediate group $(\mathbf{n}=\mathbf{2 4})$ & Initial medical group $(\mathbf{n}=\mathbf{6})$ \\
\hline 0 & 4 & 0 \\
1 & 4 & 0 \\
2 & 4 & 1 \\
3 & 0 & 0 \\
4 & 3 & 0 \\
5 & 5 & 1 \\
6 & 4 & 4 \\
\hline
\end{tabular}

Description of mRS: $0=$ no symptoms; $1=$ no significant disability, able to carry out all usual activities, despite some symptoms; $2=$ slight disability, able to look after own affairs without assistance, but unable to carry out all previous activities; 3 = moderate disability, requires some help, but able to walk unassisted; $4=$ moderately severe disability, unable to attend to own bodily needs without assistance, and unable to walk unassisted; $5=$ severe disability, requires constant nursing care and attention, bedridden, incontinent; $6=$ dead.

DiEusanio and colleagues ${ }^{7}$ reported that 64 patients with CVA and 36 patients with coma underwent surgical management, with brain injury reversal achieved in $80.4 \%$ and $74.2 \%$ of their patients with CVA and coma, respectively. ${ }^{7}$ They concluded that patients selected to undergo surgery showed a frequent reversal of neurologic deficits. Our neurologic results are comparable to those demonstrated by DiEusanio and colleagues. Conzelmann and colleagues ${ }^{18}$ reported that of 2137 patients with AADA who were enrolled in the multicenter prospective German Registry of AADA, $433(20.2 \%)$ had transient or persistent neurologic dysfunction, including CVA in 159 patients and coma in 163 patients. ${ }^{18}$ Preoperative neurologic dysfunction was resolved in $62.1 \%$ of the neurologically compromised patients. Conzelmann and colleagues ${ }^{18}$ demonstrated that neurologic dysfunction was resolved in the majority of unconscious/comatose patients who underwent surgery for AADA. The same conclusion was observed for patients who had experienced a stroke. ${ }^{18}$ These data strongly support immediate surgery for patients with AADA who present with cerebral ischemia (Table 3).

Brain temperature is an important variable in determining the outcome of cerebral ischemia, and our strategy of inducing initial deep hypothermia during the repair stage, followed by mild hypothermia in intensive care, may enhance the benefits of therapeutic hypothermia. In addition, magnesium infusion combined with therapeutic hypothermia was used in our protocol. Magnesium has been shown to have a reproducible neuroprotective effect in experimental models of cerebral ischemia. However, no randomized clinical trial has confirmed the neuroprotective effect on stroke in humans. ${ }^{19}$ Currently, the Field Administration of Stroke Therapy-Magnesium trial is being conducted for patients with acute stroke, ${ }^{20,21}$ and Zhu and colleagues $^{22}$ reported that mild hypothermia combined with magnesium treatment has synergistic neuroprotective effects and reduces brain injury. ${ }^{21,22}$ Those studies suggest that our strategy of magnesium infusion combined with therapeutic hypothermia contributed to our positive results.

Long-term outcomes in patients with AADA complicated by coma were strongly related to improvements in their neurologic deficit. In our study, there were significant differences in the survival between patients with coma and patients without coma, and between comatose patients who underwent immediate repair and patients who were initially administered medical treatment. In addition, there was a strong correlation between neurologic recovery after aortic repair and better long-term survival (Figure 1, B). These findings are comparable to those produced by Morimoto and colleagues, ${ }^{17}$ who reported that the chances of surviving for 5 years was significantly lower in patients without neurologic improvement compared with those who did show improvement $(33 \% \pm 12 \%$ vs $84 \% \pm 7 \%)$. DiEusanio and colleagues ${ }^{7}$ demonstrated that Cox proportional hazards regression analysis indicated hypotension/shock/tamponade

TABLE 3. Overview of current literature of acute type A aortic dissection with cerebrovascular accident or coma

\begin{tabular}{|c|c|c|c|c|c|c|c|c|c|}
\hline Author & Year & $\begin{array}{l}\text { Initial treatment } \\
\text { medical/surgical }\end{array}$ & $\begin{array}{l}\text { No. of } \\
\text { cases }\end{array}$ & CVA & Coma & $\begin{array}{l}\text { Time from onset } \\
\text { to OR (median) }\end{array}$ & Death & $\begin{array}{c}\text { Mortality } \\
(\%)\end{array}$ & $\begin{array}{l}\text { Neurologic } \\
\text { recovery }\end{array}$ \\
\hline Tanaka and colleagues ${ }^{1}$ & 2005 & Surgical & 11 & 11 & 11 & $6 \mathrm{~h}$ & 7 & 63.6 & $36 \%$ \\
\hline \multirow[t]{2}{*}{ Estrera and colleagues ${ }^{4}$} & 2006 & Medical & 2 & 2 & 2 & N/A & 2 & 100.0 & 0 \\
\hline & & Surgical & 14 & 14 & N/A & $9 \mathrm{~h}$ & 1 & 7.1 & $57 \%$ \\
\hline \multirow[t]{2}{*}{ Pocar and colleagues ${ }^{5}$} & 2006 & Medical & 3 & 3 & 3 & N/A & 3 & 100.0 & 0 \\
\hline & & Surgical & 5 & 5 & 5 & $7 \mathrm{~h}$ & 0 & 0.0 & $80 \%$ \\
\hline \multirow[t]{2}{*}{ Tsukube and colleagues ${ }^{6}$} & 2011 & Medical & 6 & 6 & 6 & N/A & 4 & 66.7 & $17 \%$ \\
\hline & & Surgical & 21 & 21 & 21 & $3.4 \mathrm{~h}$ & 3 & 14.3 & $86 \%$ \\
\hline Morimoto and colleagues $^{17}$ & 2011 & Surgical & 41 & 41 & 7 & $6.5 \mathrm{~h}$ & 6 & 14.6 & $63 \%$ \\
\hline Conzelmann and colleagues ${ }^{18}$ & 2012 & Surgical & 433 & 159 & 168 & N/A & N/A & N/A & $62.1 \%$ \\
\hline \multirow[t]{2}{*}{ DiEusanio and colleagues ${ }^{7}$} & 2013 & Medical & 39 & 21 & 18 & N/A & 34 & 87.2 & $12.8 \%$ \\
\hline & & Surgical & 99 & 63 & 36 & $13.8 \mathrm{~h}$ & 33 & 33.3 & $\begin{array}{l}74.2 \% \text { in coma cases } \\
77.4 \% \text { in CVA cases }\end{array}$ \\
\hline \multirow[t]{2}{*}{ Total } & & All medical treatment & 50 & 32 & 29 & N/A & $43 / 50$ & 86.0 & $14.0 \%(7 / 50)$ \\
\hline & & All surgical treatment & 625 & 314 & 248 & $(3.4-13.8) \mathrm{h}$ & $50 / 191$ & 26.2 & $64.9 \%(394 / 607)$ \\
\hline
\end{tabular}

CVA, Cerebrovascular accident; N/A, not applicable; $O R$, operating room. 
and renal failure as significant independent predictors of reduced 5-year survival. In contrast, surgical management was protective against follow-up mortality.

\section{Study Limitations}

First, this is a single-center study, with a small sample size and retrospective analysis. Second, there was no true control group. All of the patients who met our surgical strategy underwent immediate aortic repair. Third, presenting with coma is one of the strongest indicators of extensive stroke. However, the cause of coma during AADA is multifactorial. ${ }^{4,6,7,16}$ These factors include malperfusion from the dissecting flap occluding the great vessels, thromboembolism in the brain circulation from thrombus in the dissecting lumen, and the manifestation of hypoxic encephalopathy due to low cardiac output in patients with cardiac tamponade. In addition, the aforementioned factors are often complicated.

Given that we placed the highest priority on immediate aortic repair and were not able to conduct timeconsuming examinations in all cases, we did not completely determine the cause of coma before surgery in our study.

\section{CONCLUSIONS}

Aortic repair, if performed within several hours from the onset of symptoms, contributed to the satisfactory early and long-term recovery of consciousness and function for AADA complicated by coma. Immediate aortic repair is warranted even if AADA is complicated by coma.

The authors acknowledge the support of the emergency department of Japanese Red Cross Kobe Hospital and Hyogo Emergency Medical Center, and thank the following colleagues from the Departments of Neurology, Neurosurgery, Anesthesiology, and Emergent Medicine for support: Yukihiro Yoneda, MD, Masashi Yamamoto, MD, Yoshie Hara, MD, Junichi Araki, MD, Takashi Tsukiji, MD, Ryoichi Mizoue, MD, Masato Kobayashi, MD, Tetsuya Miyamoto, MD, and Akihiro Usui, MD.

\section{References}

1. Tanaka H, Okada K, Yamashita T, Morimoto Y, Kawanishi Y, Okita Y. Surgical results of acute aortic dissection complicated with cerebral malperfusion. Ann Thorac Surg. 2005;80:72-6.

2. Fann JI, Sarris GE, Miller DC, Mitchell RS, Oyer PE, Stinson EB, et al. Surgical management of acute aortic dissection complicated by stroke. Circulation. 1989; 80:I257-63.

3. Iliescu VA, Dorobantu LF, Stiru O, Bubenek S, Miclea I, Rugina M, et al. Combined cardiac-neurosurgical treatment of acute aortic dissection, stroke, and coma. Tex Heart Inst J. 2008;35:200-2.

4. Estrera AL, Garami Z, Miller CC, Porat EE, Achouh PE, Dhareshwar J, et al. Acute type A aortic dissection complicated by coma: can immediate repair be performed safely? J Thorac Cardiovasc Surg. 2006;132:1404-8.

5. Pocar M, Passolunghi D, Moneta A, Mattioli R, Donatelli F. Coma might not preclude emergency operation in acute aortic dissection. Ann Thorac Surg. 2006;81: 1348-51.

6. Tsukube T, Hayashi T, Kawahira T, Haraguchi T, Matsukawa R, Kozawa S, et al. Neurological outcomes after immediate aortic repair for acute type A aortic dissection complicated by coma. Circulation. 2011;124:S163-7.
7. DiEusanio M, Patel HJ, Nienaber CA, Montgomery DM, Korach A, Sundt TM, et al. Patients with type A acute aortic dissection presenting with major brain injury: should we operate on them? J Thorac Cardiovasc Surg. 2013;145: S213-21.

8. Lyden P, Brott T, Tilley B, Welch KM, Mascha EJ, Levine S, et al. Improved reliability of the NIH Stroke Scale using video training. NINDS TPA Stroke Study Group. Stroke. 1994;25:2220-6.

9. van Swieten JC, Koudstaal PJ, Visser MC, Schouten HJ, van Gijn J. Interobserver agreement for the assessment of handicap in stroke patients. Stroke. 1988;19: 604-7.

10. Hayashi T, Tsukube T, Yamashita T, Haraguchi T, Matsukawa R, Kozawa S, et al. Impact of controlled pericardial drainage on critical cardiac tamponade with acute type A aortic dissection. Circulation. 2012;126:S97-101.

11. Fukuda I, Imazuru T. Intentional delay of surgery for acute type A dissection with stroke. J Thorac Cardiovasc Surg. 2003;126:290-1.

12. Cambria RP, Brewster DC, Gertler J, Moncure AC, Gusberg R, Tilson MD, et al. Vascular complications associated with spontaneous aortic dissection. J Vasc Surg. 1988; 7:199-209.

13. Ergin MA, Galla JD, Lansman S, Griepp RB. Acute dissections of the aorta. Current surgical treatment. Surg Clin North Am. 1985;65:721-41.

14. Geirsson A, Szeto WY, Pochettino A, McGarvey ML, Keane MG, Woo YJ, et al. Significance of malperfusion syndromes prior to contemporary surgical repair for acute type A dissection: outcomes and need for additional revascularizations. Eur J Cardiothorac Surg. 2007;32:255-62.

15. Centofanti P, Flocco R, Ceresa F, Attisani M, La Torre M, Weltert L, et al. Is surgery always mandatory for type A aortic dissection? Ann Thorac Surg. 2006;82: 1658-63.

16. Hiratzka LF, Bakris GL, Beckman JA, Bersin RM, Carr VF, Casey DE Jr, et al. 2010 ACCF/AHA/AATS/ACR/ASA/SCA/SCAI/SIR/STS/SVM guidelines for the diagnosis and management of patients with Thoracic Aortic Disease. Circulation. 2010;121:e266-369.

17. Morimoto N, Okada K, Okita Y. Lack of neurologic improvement after aortic repair for acute type A aortic dissection complicated by cerebral malperfusion: predictors and association with survival. J Thorac Cardiovasc Surg. 2011;142: $1540-4$.

18. Conzelmann LO, Hoffmann I, Blettner M, Kallenbach K, Karck M, Dapunt O, et al; GERAADA Investigators. Analysis of risk factors for neurological dysfunction in patients with acute aortic dissection type A: data from the German Registry for Acute Aortic Dissection type A (GERAADA). Eur J Cardiothorac Surg. 2012;42:557-65.

19. Westermaier T, Stetter C, Kunze E, Willner N, Raslan F, Vince GH, et al. Magnesium treatment for neuroprotection in ischemic diseases of the brain. Exp Transl Stroke Med. 2013;5:6.

20. Saver JL, Kidwell C, Eckstein M, Starkman S. Prehospital neuroprotective therapy for acute stroke: results of the Field Administration of Stroke TherapyMagnesium (FAST-MAG) pilot trial. Stroke. 2004;35:106-8.

21. Saver JL, Starkman S, Eckstein M, Stratton S, Pratt F, Hamilton S, et al. FASTMAG Investigators and Coordinators. Methodology of the Field Administration of Stroke Therapy - Magnesium (FAST-MAG) phase 3 trial: Part 2-prehospital study methods. Int J Stroke. 2014;9:220-5.

22. Zhu H, Meloni BP, Moore SR, Majda BT, Knuckey NW. Intravenous administration of magnesium is only neuroprotective following transient global ischemia when present with post-ischemic mild hypothermia. Brain Res. 2004;1014:53-60.

\section{Discussion}

Dr John Elefteriades (New Haven, Conn). I congratulate the authors for their excellent clinical results with a difficult group of patients, those with type A dissection presenting with neurologic injury.

Surgeons have traditionally avoided such patients for fear of inducing intracranial hemorrhage from the heparin necessary from cardiopulmonary bypass and out of concern that the depressed neurologic status would continue postoperatively, leading to mortality or impaired quality of life.

Your good results show us an important point, and that is the surprising and fortunate principle that resecting the ascending aorta and putting the dissected layers together in the distal anastomosis miraculously restore perfusion to all branch organs and 
branch vessels, including the brain in the majority of cases; that is what your study indicates for us.

I have 3 questions. First, you didn't really give us the results of the CT imaging in your patients. How many patients had infarcts on $\mathrm{CT}$ of the brain and how did the patients with discernible infarcts fare?

Dr Tsukube. In terms of CT scans of the brain, all of the patients had CT scans before immediate repair. Of 24 patients, only 3 had the early ischemic sign that I presented in my presentation, but there was no infarction in other cases. Because the CT scan was not sensitive enough to demonstrate ischemic change within 3 or 4 hours after onset of ischemic stroke, magnetic resonance imaging is a better modality and more sensitive to demonstrate early signs of ischemic change. However, in the setting of AADA, it is difficult to perform magnetic resonance imaging.

Dr Elefteriades. Do you think any of the patients with coma had the coma on the basis of hemodynamic embarrassment, hypotension, or perhaps the narcotics given for intubation?

Dr Tsukube. Of 24 patients, 7 demonstrated bilateral carotid involvement, but 12 had right carotid artery dissection only and 5 had no carotid involvement.

In terms of mechanism of coma, unilateral obstruction of the carotid artery may not be enough to become comatose. Bilateral obstruction of the carotid artery or unilateral carotid obstruction with low blood pressure is the highest factor for our patients. For instance, pericardial effusion and cardiac tamponade are factors that decrease the blood perfusion of the brain and lead to coma.

Dr Elefteriades. Can you give us a precise algorithm for how to evaluate and treat patients presenting with type A dissection and coma?
Dr Tsukube. We have a simple algorithm because if we can transport the patient to the operating room within several hours from onset, we just go ahead and do this.

However, during preparation of the operating room, it is important to stabilize the hemodynamics if we can because as I explained to you, systemic blood pressure is important to manage before surgery, especially for patients who have the ischemic brain lesions.

In terms of reversibility of the brain, there are 2 major factors for the reversibility. One is the time, and the other is the amount of residual blood flow of the ischemic area. Time is important. Also, maintaining the hemodynamics is important too. Regarding contraindication for this surgery, one is CT scan of the bleeding in the brain. Also, if a patient has a dependent life before surgery, we don't operate.

Dr Thomas Gleason (Pittsburgh, $\mathrm{Pa}$ ). Expanding on Dr Elefteriades' first and third questions, it's not surprising to me that the CT scans were negative in most of the patients because a CT scan less than 24 hours old is going to be normal.

Would it not be more beneficial in helping you to adjudicate which patients to and not to operate on to do a CT angiography, specifically a CT perfusion study, to define what the relative cerebral blood flow is in different regions?

Dr Schafers. Contrast CT.

Dr Tsukube. For the brain, we did not take a contrast CT, but for the diagnosis of aortic dissection, we use contrast CT. In our strategy, we don't want to take the time to evaluate before surgery, just go ahead and do the operation. The signs are important, and we performed CT to observe if there is no bleeding in the brain. Otherwise, we just go ahead to the operation. 